\title{
Survey of the academic use of planetariums for undergraduate education
}

\author{
Daniel J. Everding ${ }^{*}$ \\ Department of Astrophysical and Planetary Sciences, The University of Colorado Boulder, \\ Boulder, 80309 Colorado, USA \\ John M. Keller $\odot^{\dagger}$ \\ Fiske Planetarium, Department of Astrophysical and Planetary Sciences, \\ The University of Colorado Boulder, Boulder, 80309 Colorado, USA
}

(Received 27 November 2019; accepted 18 August 2020; published 23 October 2020)

\begin{abstract}
We present the analysis of the planetarium usage survey (PLUS), a two-part, mixed-methods initial study investigating planetarium use in the U.S. by undergraduate learners. Seventy-seven planetariums situated on college or university campuses within the U.S. completed an online survey during the fall of 2018 with 11 of those participating in online or phone interviews during the summer of 2019. Planetarium representatives described how their facilities were being used, types of subject materials that were being taught, what content styles are used, and how often learners are attending lessons in the planetarium. Results suggest that undergraduate learners in a planetarium environment are primarily novice, non-STEM (science, technology, engineering, and mathematics) majoring students, learning principally astronomy content, receiving instruction from a live presenter approximately once per month within a given course, for the purpose of receiving visualization-based scaffolding. Audience response systems like iClickers do not appear to be in widespread use in collegiate planetariums, and presented subject matter shows greater variety in planetariums with digital projector capacity as opposed to those with only analog projectors. Refinements to PLUS and future research plans are described.
\end{abstract}

DOI: 10.1103/PhysRevPhysEducRes.16.020128

\section{INTRODUCTION}

The extant literature for astronomy education research has shown that groups of students are able to improve their understanding of astronomical concepts in planetarium settings [1-3]. The planetarium environment, in both formal $[4,5]$ and informal contexts [6], uniquely provides an immersive visual experience that translates into greater learning for younger, elementary learners $[7,8]$ as well as more experienced, collegiate learners $[4,5]$. The planetarium environment is also able to help students construct more complete views by presenting multiple frames of reference unavailable in typical classroom settings [9]. Fulldome environments could be highly useful, specifically to the education of undergraduate astronomy learners [10], who often actively maintain misconceived or incorrect visualizations of the Universe from traditional classroom environments [11].

\footnotetext{
*Daniel.Everding@colorado.edu

†John.M.Keller@colorado.edu
}

Published by the American Physical Society under the terms of the Creative Commons Attribution 4.0 International license. Further distribution of this work must maintain attribution to the author(s) and the published article's title, journal citation, and DOI.
The various perspectives, orientations, and vantage points needed to fully understand astronomical phenomena are usually beyond the two-dimensional (2D) presentation capacity of most classroom settings, making astronomy a historically difficult subject to teach [10]. Planetarium facilities are constantly renovating to keep up with the advances of technology, and many facilities are now equipped with the ability to render immersive, virtual environments in addition to showing traditional projected positions of the various celestial bodies [10,12]. This allows for a learning space that can more fully illustrate astronomical concepts without leaving the learner to "fill in the gaps" between a 2D illustration in a textbook and an actual $3 \mathrm{D}$ phenomenon $[4,10,13,14]$. The digital planetarium environment has been demonstrated to show measurable learning of both Earth and space science concepts in young children [7], adding weight to the proposition of using planetariums for the instruction of nonastronomical content at the collegiate level $[7,12,15]$.

In spite of these instructional benefits, planetariums seem to remain a "special occasion" educational setting for undergraduate astronomy learners, being visited by a given class no more than a handful of times a year, let alone in a given semester; these more informal trips to the planetarium are marked by visits that are typically shorter 
than a corresponding classroom visit [16]. Singular, selfcontained planetarium visits have been discouraged since analysis by Sunal [17] found them to be inferior to alternate planetarium instructional strategies, and infrequent visits to unfamiliar settings like planetariums might induce a more difficult learning environment. The "novelty" of the planetarium setting can require more attention and cognitive demand than a typical classroom for learners stepping into an unfamiliar environment $[18,19]$. Earlier assessments of planetarium use showed little to no benefit in the planetarium environment [17], but more recent evaluations of past planetarium studies have since demonstrated the benefits of planetarium instruction [1].

Viewing these findings with recent data demonstrating a planetarium's advantages over the traditional collegiate classroom [5,14], we view these findings as incentive that further investigations are needed into how best a collegiate planetarium's benefits can be maximized, a point raised during a meta-analysis of planetarium studies presented by Brazell and Espinoza [1].

Evidence continues to mount supporting the gains provided by a collegiate learning environment that aligns with student-centered, peer-to-peer, and interactive instructional strategies [20-22]. These environments, often facilitated by the use of classroom technology (iClickers, for example), have been shown to promote better retention among learners and add to the traditional classroom experience $[21,23,24]$ at both the undergraduate and graduate level for both large and small classes [25]. It is reasonable to ask how these technologies have also been integrated into planetarium environments, as part of the effort to more fully integrate interactive pedagogies into collegiate curriculum.

We contend that a general survey of undergraduate-level, formal planetarium learning needs to be established, specifically to answer the following questions.

1. How often are planetariums used in the education of undergraduate astronomy learners? Is a typical astronomy class visiting a planetarium regularly or rarely?

2. What are planetarium learners being taught? Is astronomy the only subject planetariums formally instruct? How is content being presented to learners?

3. How are planetariums trying to actively engage their learners? Are planetariums effectively utilizing interactive classroom technologies and what types?

4. Which astronomical topics are seen as well instructed in planetarium environments? Which are seen as poorly instructed? How can these findings motivate and guide efforts to enhance astronomy learning in fulldome environments?

The answers to these questions can guide systematic efforts to examine planetarium effects on undergraduate astronomy learners by informing researchers of how planetariums are actually being used by university learners, why these learners are taking part in planetarium instruction, how instruction is being delivered, and by formally documenting how planetariums are currently being used to advance collegiate education.

\section{THEORETICAL FRAMEWORK}

Our review of the existing research suggests that most, if not all, past investigations into planetarium learning rests upon a common assumption: a planetarium is a learning environment for astronomy [1-3]. The exclusion of other disciplines like physics or Earth science was sound when planetariums were first constructed around analog star ball projectors, but the progressive incorporation of full or hybrid digital systems operating with dome mounted projectors may have expanded the set of possible material appropriate for a planetarium environment [7,10,12].

Learning environments may be broadly separated into two categories: formal and informal [26]. As collegiate learners are likely to be instructed in a primarily formal context with a well-defined set of learning outcomes, we have adopted the research guidance pertinent to a formal, in-dome environment where "a structured and controlled planetarium program" is the presumed method of learning $[16,26]$. As a point of contrast for the reader, we offer astronomy classes and astronomy clubs as an exemplary pair of in-dome learning environments that typify the formal-informal axis outlined by Plummer et al. [16].

A truly generalized answer to "how students learn," especially in planetarium environments, remains a topic of active research; however, for this study we will adopt an initial framework obliging the use of particular learning environments, like a planetarium, by instructors to promote specific learning outcomes in their students. We have adopted the learning environment, learning process, and learning outcome (LEPO) framework for this study [27]. Like many frameworks obliging an activity theory mindset, LEPO considers the processes and outcomes of learning in the context of the learning environment. These three cornerstones are interacted with by both the learner and instructor during the act of learning [27]. While more complex frameworks exist in the context of technology-rich astronomy education (see, e.g., Barab et al. [28]), we have agnostically chosen this simpler framework upon which to build this baseline study.

This investigation assumes a framework for planetarium learners characterized by the following traits: learners are in a formal instructional setting where the learning process closely mirrors that of a usual collegiate classroom, with the instructor acting as a source or distributor of knowledge; learning outcomes are principally in the cognitive domain, such that students can be evaluated with some kind of definite assessment to gauge their learning; and presented content is often astronomy based and serves as a well-defined complementary instruction mode to the regular classroom. Thus, the planetarium forms the environment 
corner of the LEPO framework, with learners and instructors engaging with the environment through usual classroom processes to achieve the desired outcome [27].

\section{METHODS AND INVESTIGATION}

This initial study was constructed around a mixedmethods analysis, with study participants (representatives of higher education planetarium facilities) being asked both quantitative and qualitative question items using multiple instruments. This mixed-methods approach blended two investigation strategies previously employed in planetarium education research: a survey-style instrument (similar to Fraknoi [29]) and an interview-style instrument (similar to Croft [15] and Small and Plummer [30]). Fraknoi [29] surveyed astronomy instructors at nonresearch institutions to gain insight into instructors "outside" the sphere of research institutions and top liberal arts colleges. Small and Plummer [30] explored the opinions of planetarium professionals about planetarium experiences, focusing on goals for child learners, using an interview protocol. Croft [15] likewise interviewed planetarium professionals to explore an apparent conflict between educational and entertainment goals in a planetarium. Like the above studies, this investigation collects primary data from campus professionals with direct experience about how instructors are using their facilities, with particular attention to higher education settings. Our approach offers three types of primary data that together serve to inform our research questions: quantitative data from closed-ended multiple-choice survey questions, semiquantitative data from trend coding open-ended survey questions, and qualitative data from open-ended interview questions.

This work sought to further our understanding of planetarium use for undergraduate learners by building a set of survey constructs around our research questions. These constructs are shown in Table I along with a description of the associated guiding survey questions used to test each construct. Following the distribution strategies in previous works [29,30], we chose to distribute our survey to a large sample of appropriate participants.

The sample population was taken from the International Planetarium Society (IPS) catalog, available to the public from the professional organization Web page. This catalog contains self-reported information from IPS members, including information such as contact information, general institution information, and structural information describing the facility (theater seat counts, orientation, and projector capabilities). The sample population drawn from this catalog were those institutions that identified themselves with the institution code "Univ/College," describing planetariums located on university or college campuses.

Participants were representatives of planetarium facilities located on higher education campuses (e.g., planetarium directors and education coordinators). Participants were posed questions during an initial survey period and a subset
TABLE I. Survey constructs of the PLUS study. Constructs were constructed from our emergent research questions and were explored with both online survey question items and follow-up interview responses.

\begin{tabular}{lc}
\hline \hline Research construct & Guiding questions \\
\hline $\begin{array}{c}\text { Learner populations and } \\
\text { use frequency }\end{array}$ & $\begin{array}{c}\text { How often are planetariums used in } \\
\text { the education of undergraduate } \\
\text { astronomy learners? } \\
\text { Is a typical astronomy class visiting a } \\
\text { planetarium regularly or rarely? }\end{array}$ \\
$\begin{array}{c}\text { Subject materials and } \\
\text { projector-dependent } \\
\text { content variety }\end{array}$ & $\begin{array}{c}\text { What are planetarium learners being } \\
\text { taught? }\end{array}$ \\
$\begin{array}{c}\text { Is astronomy the only subject } \\
\text { planetariums formally instruct? } \\
\text { and perceived } \\
\text { environmental traits }\end{array}$ & $\begin{array}{c}\text { How are planetariums trying to } \\
\text { actively engage their learners? } \\
\text { Are planetariums effectively utilizing } \\
\text { interactive classroom technologies } \\
\text { and what types? }\end{array}$ \\
& $\begin{array}{c}\text { How can these findings motivate and } \\
\text { guide efforts to enhance astronomy }\end{array}$ \\
& learning in fulldome \\
environments?
\end{tabular}

of these participants volunteered for one-on-one interviews during the summer of 2019 to further explore trends emerging from the initial survey period. These additional interviews were to triangulate the initial findings emergent from the online survey data, and also to guide both validation efforts and development of a refined survey instrument for future use.

\section{A. Planetarium usage survey (PLUS) instrument: Fall 2018}

Potential respondents were invited to participate en masse with a Qualtrics survey link embedded in an invitation email; approximately 261 institutions were invited to participate in the survey. Ninety-three such institutions $(\sim 36 \%)$ were registered by Qualtrics as having opened the survey, with 77 of those $(\sim 83 \%)$ fully completing the survey. Data from incomplete surveys are included in these analyses when available-blank entries were removed from each question's response data before any analysis was done. Respondents had 28 days to complete this survey and reminder messages were sent throughout this time to encourage survey completion.

To verify the sample range of this study, a comparison was drawn between the listed seat counts in the IPS catalog 


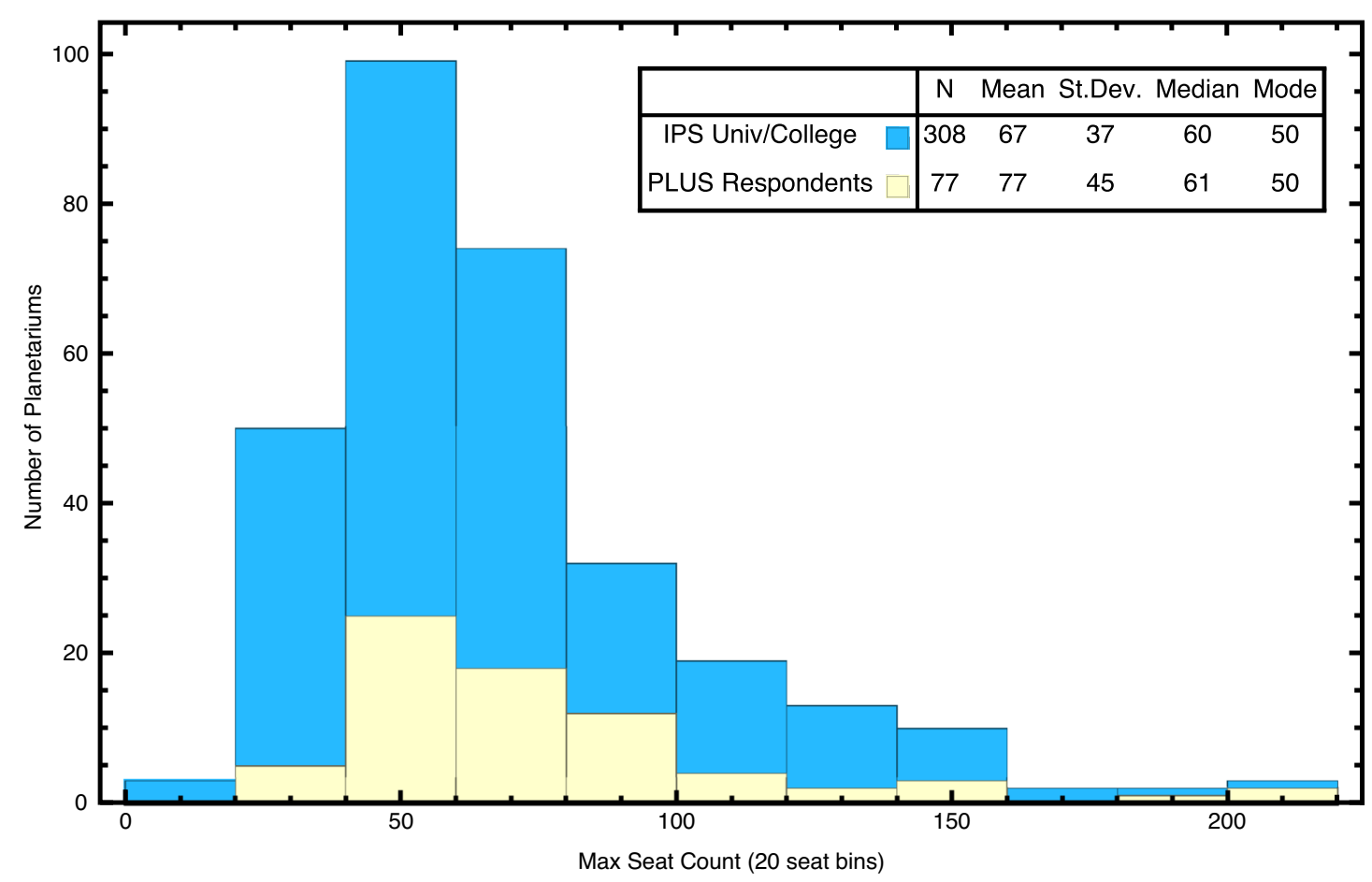

FIG. 1. Histograms of IPS catalog seat count data for all respondents indicating "Univ/College" compared with IPS catalog seat count data for facilities of PLUS respondents. Similarity in these distributions' descriptive statistics supports this study's findings as characteristic of the nationwide group.

of all facilities listed under Univ/College and the facilities of planetarium usage survey (PLUS) respondents (Fig. 1, blue and white distributions, respectively). This was accomplished by cross-referencing the PLUS respondents' contact information against the contact information in the IPS catalog and extracting the corresponding seat countsrespondents were not asked to enumerate the seat counts of their respective planetariums.

Four descriptive statistics were drawn from the two distributions, shown in the legend of Fig. 1. Assuming the IPS catalog is the "true" distribution of seat counts, the distribution corresponding to the PLUS respondents closely maps that of the IPS Univ/College catalog. A Kolmogorov-Smirnov (KS) test was run between the two distributions, assuming the IPS Univ/College catalog distribution was the true distribution. To a significance level of $0.05\left(U_{\mathrm{KS}}=0.084, p=0.695\right)$, a KS test fails to reject the null hypothesis that the two datasets have the same distribution, allowing us to conclude the PLUS is a meaningful representation of the collegiate planetarium community.

\section{B. PLUS interview instrument: Summer 2019}

For the follow-up interviews, a selection scheme was devised to shorten the available contact list rather than send out an interview invitation to all original respondents. Invitations were sent out to those respondents who completed the Qualtrics survey and whose responses to three of the survey's questions were collectively deemed as "complete." This designation was made with the following scheme.

1. For each completed survey, the number of distinct subjects taught (normalized by six subjects), the number of seats during a regular class visit (normalized by 180 seats), and the word count of the first free response question ("What subjects do you think are instructed well in a planetarium"; normalized by 114 words) were compiled as an ordered triplet.

2. Each ordered triplet had its Cartesian "completeness score" $D$ calculated as the distance from the "origin" of the three-dimensional "completeness space." Quality scores could take any value between 0 and 1.73 .

3. The median quality score $D_{\text {med }}$ was determined for the entire respondent pool. Those respondents whose completeness score equalled or exceeded the median quality score $\left(D \geq D_{\text {med }}\right)$ were extended an invitation to be interviewed.

This strategy was used to identify prospective interviewees who might provide the most descriptive insight into how medium to large planetariums are engaging undergraduates in both astronomy and other content. While this strategy may have been biased against respondents who were less descriptive in their written survey responses or who maintained smaller facilities, our choice of using the statistical median as the lower cutoff helped alleviate overselection of outlying high-value quality scores. 
TABLE II. Pseudonym, official title, home institution type, and general planetarium descriptions of this study's interview subjects. Institution types were determined by cross-referencing respondents' host institutions against the Carnegie classification catalog [31]. R1: Doctoral university—very high research activity; R2: Doctoral university—high research activity; D/PU: Doctoral/professional university; Bacc. College_A\&S: Baccalaureate college with arts and sciences focus; Assoc. College: Associate's college; CC: Community college.

\begin{tabular}{llll}
\hline \hline Pseudonym & \multicolumn{1}{c}{ Official title } & Institution type & Planetarium type \\
\hline Dr. White & Planetarium director; associate professor of astrophysics & R2 & Digital \\
Professor Green & Planetarium director; instructor in mathematics & Bacc. College-A\&S & Analog \\
Dr. Blue & Astronomy department chair & Bacc. College-A\&S & Analog \\
Dr. Red & Astronomy faculty & CC/Assoc. College & Digital \\
Dr. Violet & Professor of physics and astronomy & CC/Assoc. College & Digital \\
Dr. Yellow & Planetarium director & D/PU & Digital \\
Dr. Indigo & Astronomy faculty; planetarium teaching coordinator & R1 & Digital \\
Professor Orange & Educational programs manager & R1 & Digital \\
Dr. Black & Planetarium director; auxiliary faculty in astronomy & R1 & Digital \\
Dr. Brown & Planetarium director; professor in physics and astronomy & CC/Bacc. College-A\&S & Digital \\
Dr. Grey & Assistant professor in physics and chemistry & Bacc. College-A\&S & Digital \\
\hline \hline
\end{tabular}

This selection scheme selected 36 of the 77 valid respondents $(\sim 47 \%)$. Invitations to be interviewed were extended to these 36 , with the expectation that about half would be willing and available to be interviewed. Eleven of the 36 ( $\sim 31 \%$ of invitations; $\sim 14 \%$ of original 77 respondents) sat for an interview during the summer of 2019. The descriptive characteristics of the interviewees, as well as respondent pseudonyms, can be found in Table II. Individual subject quotes and discussions will be prefaced by the respondent pseudonym in this paper.

Interviews occurred for each consenting participant in one sitting, and both interview notes and recordings resulted from each interview. Each interview took approximately 90 minutes to complete and followed a semistructured procedure where participants were prompted with a question but were left to freely respond as they saw fit $[15,30]$. Participants were asked 14 open-ended questions, with possible follow-ups for clarification being asked as needed. The interview questions were crafted by us after discussion of the emergent trends from the survey data and were used to triangulate and validate the findings from the survey. Interview subjects were provided with both the interview questions beforehand and preliminary findings from the 2018 survey. Audio recordings of 10 of the 11 interviews were made-a recorder malfunction failed to record one of our interviews. We have included the text of our interview questions in Sec. IV in the appropriate sections for our research constructs (Table I).

All respondents were asked to name their planetarium, the college or university at which it is located, their official position at the college or university, and a brief description of the technological capabilities of their planetarium. Each college or university was cross-referenced with the Carnegie classification catalog to establish the sampling diversity of this study [31]. Subjects' institutions range from R1 (doctoral universities, very high research) to associate's or community college. Five of the $11(\sim 45 \%)$ institutions were doctoral degree granting institutions, three $(\sim 27 \%)$ were bachelor's degree granting institutions, two $(\sim 18 \%)$ were associate's degree granting institutions, and one $(\sim 9 \%)$ was listed as both a bachelor's and associate's degree granting institution. Of the 11 interview respondents, $10(\sim 91 \%)$ were full or partial instructor faculty at their respective institutes-the remaining interview respondent $(\sim 9 \%)$ was formally rostered as the education director of their planetarium. Nine of the 11 respondent planetariums $(\sim 82 \%)$ were partially or fully digital domes, with the remaining two $(\sim 18 \%)$ being analog only.

Finally, we note here that this study showed a less favorable sampling of analog-only planetariums during the PLUS 2019 interviews (Table III). When we consider the percent-equivalent counts of our four groups [with our assumed standard counting error applied $\left(\sigma_{k}=\sqrt{N_{k}}\right)$ ], the distribution of analog-only and digital-capable planetariums in the IPS catalog (Univ/College Only) is not statistically distinguishable from the PLUS 2018 survey. Across the four groups presented in Table III, the

TABLE III. Counts of this study's respondent planetarium's projector descriptions. PLUS 2018 projector types were found using respondent-provided planetarium names and institution extensions. Standard counting error $\left(\sigma_{k}=\sqrt{N_{k}}\right)$ is assumed for each response bin. PLUS 2018 did not sample a measurably different distribution of planetariums than would be expected from the IPS Univ/College catalog, but a slight bias against analog-only planetariums was introduced during the interview invitation process (described in text).

\begin{tabular}{lccc}
\hline \hline Group & $\begin{array}{c}\text { Respondent } \\
\text { count }\end{array}$ & $\begin{array}{c}\text { Analog- } \\
\text { Only }\end{array}$ & $\begin{array}{c}\text { Digital- } \\
\text { Capable }\end{array}$ \\
\hline $\begin{array}{l}\text { IPS catalog-Univ/College } \\
\quad \text { Only }\end{array}$ & 352 & $45.2 \%$ & $54.8 \%$ \\
PLUS 2018 survey & 77 & $38.2 \%$ & $61.8 \%$ \\
$\begin{array}{l}\text { PLUS 2019 interview } \\
\quad \text { invites }\end{array}$ & 36 & $27.8 \%$ & $72.2 \%$ \\
PLUS 2019 interviews & 11 & $18.2 \%$ & $81.8 \%$ \\
\hline \hline
\end{tabular}


percentage of digital-capable respondents remains indistinguishable throughout this study. However, the number of analog-only respondents was measurably fewer as the study progressed. We do not believe that this has imparted undue bias to this study's findings for the following reasons: the IPS catalog (Univ/College Only) has a small, measurable preference for digital-capable planetariums, triangulation of the 2018 survey data was still possible with the sample of interviewees obtained, and the interview questions did not rely on a particular projector style in order to be considered by our participants.

\section{DATA AND ANALYSIS}

The pool of available data used in this study was composed of our primary data, collected during the online survey period in fall 2018 and interview period in summer 2019 , and secondary data from the IPS catalog, specifically the list of seat counts and projector types.

Quantitative data were collected by PLUS using multiple-choice and open-ended, free-response questions. Qualitative data were collected by PLUS free-response questions-free-response data were analyzed using an iterative identification of response trends. For each question's set of responses, trends were identified and coded with generally descriptive alphabetic codes and then reanalyzed and given additional numeric codes that further described the response. Descriptive codes were generated or consolidated as necessary throughout the iterative process. The PLUS asked a total of 10 required questions, with an additional 10 possible questions being displayed depending on the respondents' selections of the required questions.

Given our comparatively small number of follow-up interviews $(N=11)$, analysis of the interview responses followed a more holistic approach similar to the approach presented by Croft [15]. Responses to each interview question were considered together and trends were identified as opposed to an iterative coding scheme. In most circumstances, our interview responses converged upon similar underlying themes or naturally partitioned themselves into distinctive groups.

We present this study's survey and interview data together for each investigation construct sought by this study. Survey and interview questions pertinent to each construct are presented in bold face-for this presentation we adopt the style of "QX.Y" to denote survey question from section "X," question "Y," and "IQ" to denote interview questions. Finally, we refer to our initial survey instrument as PLUS 1.0 and the revised future survey instrument as PLUS 2.0.

\section{A. Construct 1: Learner populations and use frequency}

Our first construct exploring who is using a planetarium environment to learn was investigated by analyzing the responses to two survey questions (Q2.1 and Q2.2) and interview discussions.

Q2.1: "Which of the following audience populations does your planetarium serve?"

During the PLUS 1.0 implementation of Q2.1 (Fig. 2, "Primary service?"), respondents were prompted to select the audience populations served by their planetarium in a pair of side-by-side selection box columns. In the left-hand column, respondents were asked to select all audience populations that make any use of their planetarium; in the right-hand column, respondents were supposed to select a single audience population that the planetarium primarily served. Because of a misunderstanding concerning the Qualtrics platform, respondents were able to select more than one "Primary" selection, and thus were able to provide more data than should have been allowed. To compensate for this possibility, data were filtered and kept if they satisfied the following conditions: the respondent selected only one option in the "Primary" column and the same selected population was also one of the selected populations in the "Any" column. Such conditions avoided any respondents who selected more than one "Primary" selection while also ensuring that their choice of "Primary" was sensible (the choice had a corresponding "Any" selection). This data collection has been refined in PLUS 2.0 (described below).

Two immediate findings emerge from these filtered data (Fig. 2). First, collegiate planetariums reliably serve almost every learner group, with the only distinct outlier being graduate students. Second, in spite of being on college campuses, these data suggest that the primary learner population served by the facilities surveyed is K-12 learners rather than four-year or community college learners. Also of interest is the complete loss of "pre- $\mathrm{K}$ " and "graduate student" learner groups in the set of "Primary service" responses. The wide selection of "Any" service populations is not surprising - we know of no planetarium that expressly excludes any of the considered learner groups from using their facilities. The "Primary" responses do not explain why collegiate planetariums are not primarily serving their own college students. These data required further probing during the interview portion of this study, described below.

Q2.2: “On average, how often is your dome used by an undergraduate or graduate astronomy class during a typical term (quarter or semester)?"

Data for undergraduate astronomy students (Fig. 3, left) are the most numerous for a frequency of "monthly"; however, there is no statistical difference with the neighboring "weekly" bin. The "daily" frequency bin is also statistically indistinguishable from the "weekly" bin, but is significantly different from the "monthly" bin. Data for graduate students are more definitive (Fig. 3, right): $81 \%$ of all respondents described the use of their planetarium by graduate-level astronomy as "never," with the next largest frequency bin being "yearly." Both the "never" and "yearly" bins are statistically distinct from one another 


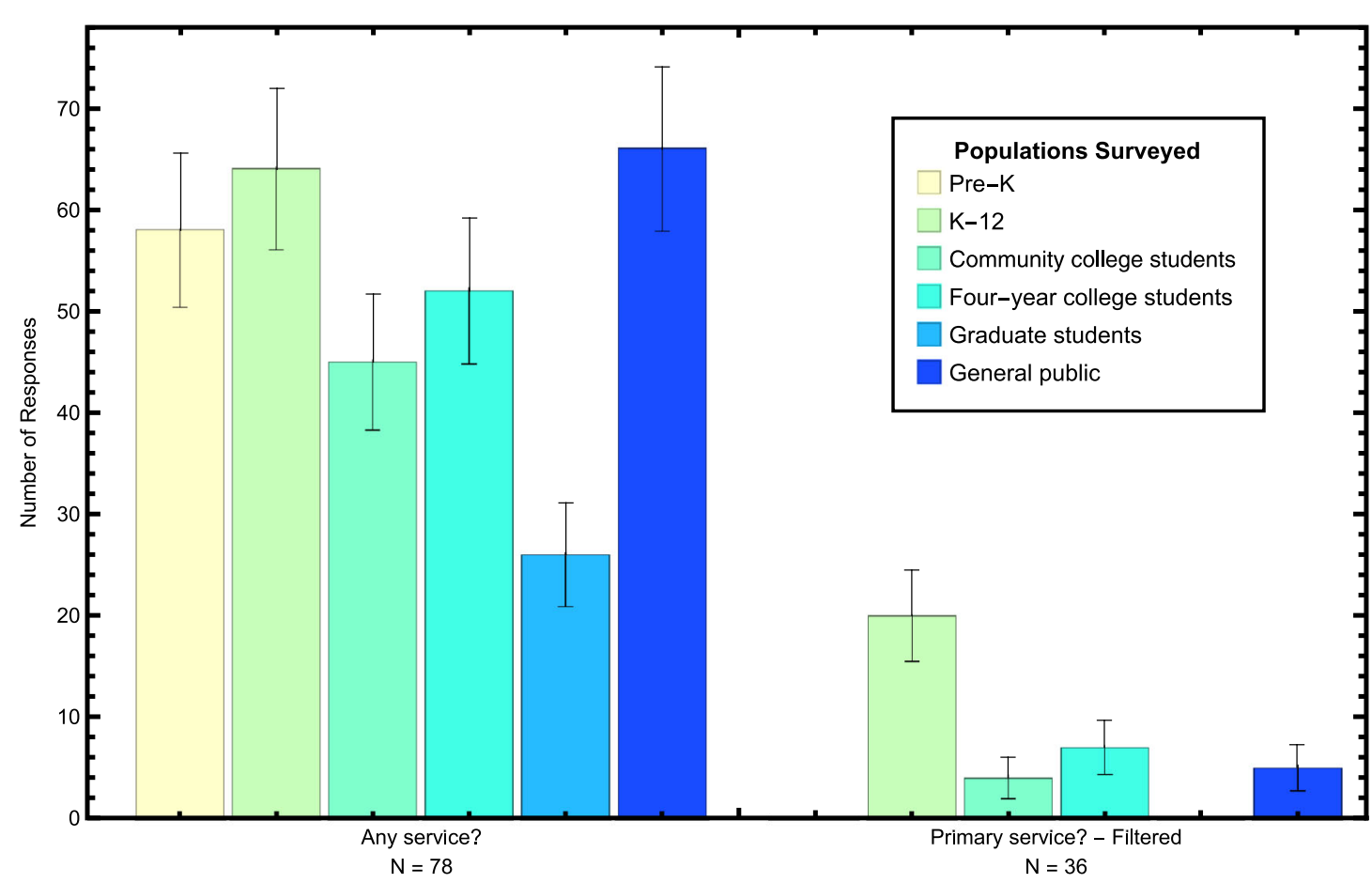

FIG. 2. Responses to Q2.1 concerning which learner populations (legend) are serviced by U.S. planetariums on college or university campuses - respondents were asked to select all populations that their planetarium served at any time (left-hand group) and which single population was their primary audience (right-hand group). Standard counting error $\left(\sigma_{k}=\sqrt{N_{k}}\right)$ is assumed for each data bin. An error in the data collection required the data to be filtered (described in text). Data reinforce findings about graduate learners' comparative lack of planetarium use, and suggest that collegiate planetariums are most commonly used by the K-12 learner group, not collegiate audiences.

and from the remaining frequency counts, which are themselves statistically indistinguishable. Our conclusions from these data are that a typical undergraduate astronomy student on a campus with a planetarium is being instructed in that environment once every week to once per month during an academic term; graduate astronomy learners do not practically use a planetarium during an academic term, if ever. Collection of these data has been refined in PLUS 2.0 (described below).

IQ: What kind of undergraduate astronomy learner is coming to your planetarium?

To clarify the planetarium usage data gathered during the survey (Figs. 2 and 3), respondents were asked to specify what kind of undergraduate astronomy learner is coming to their planetariums for instruction. All 11 respondents described their typical planetarium learner as "non-major," "non-STEM," "novice," "beginner," or a combination thereof. Three of the $11(\sim 27 \%)$ made specific mention of expert-level planetarium learners during their descriptions. These expert-level learners were described as seeking their teaching credentials for STEM (science, technology, engineering, and mathematics) courses and were not in the planetarium to learn astronomy content specifically, but rather how to present it.

Dr. Blue: "I suppose the wrinkle on that is that the advanced astronomy students are learning to use the planetarium and hone their teaching skills. ...they're not in there for a class, they're in there to learn how to give the class."

The lack of use by more experienced astronomy learners may rest on an assumption that more experienced STEM learners would not benefit from planetarium instruction because they do not "need" it:

Dr. Indigo: “...I specialize in students who are not going to be scientists, teaching them science and there, the planetarium is invaluable... we use the planetarium to teach general education astronomy... the planetarium is not as effective for a student that can do calculus because a student that can do calculus can think abstractly-they don't need a three dimensional visual representation."

We stress to the reader that this assumption was inspired by the comments from one interview and may not be representative as a samplewide trend. The contention above is that a more experienced learner should possess the ability to form the 3D constructs necessary for astronomy comprehension without the scaffolding aid of a planetarium. However, this ability could take several years of instruction to fully form [32], and assuming the spatial ability of a learner might not be advisable for an instructor. Furthermore, for astronomy specifically, even advanced learners in preservice teaching training have been demonstrated to maintain misconceptions, even after instruction [33]. When this comment is considered alongside the small number of expert-level learners and the near lack of 


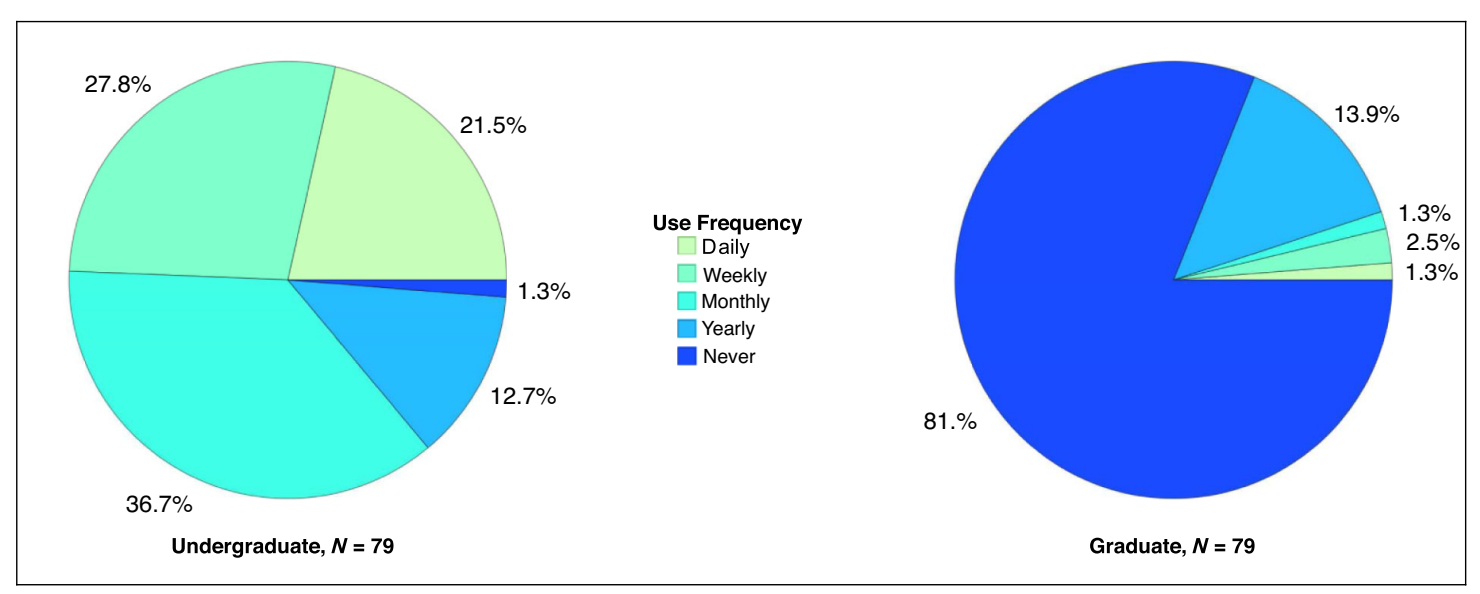

FIG. 3. Responses to Q2.2 concerning how often undergraduate- and graduate-level astronomy students are using the planetarium during a typical academic term (quarters or semesters). Undergraduate data propose a characteristic frequency between weekly and monthly; graduate data strongly contend that graduate learners do not practically use a planetarium.

graduate-level learners (Fig. 3), we contend that planetariums may be viewed as the near-unique purview of the novice, non-STEM major learner. The use of a planetarium for more advanced learners may be seen as unnecessary, but the veracity of this requires further dedicated study.

Respondents were also asked to explain why their planetariums were primarily used by their respective primary audiences. Respondents who selected "K-12" as their primary audience $(\sim 64 \%)$ voiced one principal reason: population demand. K-12 learner groups, particularly younger learners, often partake in a planetarium visit during a field trip during their general science units. The inclusion of planetarium resources into K-12 curriculum for educational purposes has been recommended in the past [1]. More recent curriculum considerations for the K-12 learner population stress basic astronomical content knowledge [34,35], for which a planetarium is almost uniquely qualified to serve as an instructional environment $[10,36]$.

Dr. Yellow: "I think that a lot of people went to a planetarium when they were in grade school, so they think of a planetarium as being a place for field trips."

This point is further reinforced when one weighs the financial considerations of a planetarium which may need to fund itself through ticket sales - the larger number of K12 students could provide a reliable revenue stream to a planetarium, and may thus be more heavily advertised to those learner groups as opposed to college faculty.

\section{B. Construct 2: Subject materials and projector-dependent variety}

To probe what materials are being presented and how a planetarium's projector type may impact the variety of those materials, our second research construct was initially probed with two "select all that apply" style questions. Respondents were asked to select which subjects are instructed in their planetariums and to specify how many students attend a typical class for each selected subject. As a follow-up for each subject, respondents were asked to further specify which disciplines for each subject were instructed in their planetariums:

Q2.3: "Which, if any, subjects are taught in your planetarium? Where possible, please also include an approximate number of students instructed during a typical class period in the spaces included."

Q2.3a-f: "Which disciplines of [previously selected subject] are instructed in your facility?"

For the purposes of this study, "subject(s)" will refer to the large, overarching academic categories shown in the left-hand column of Table IV. These subjects are intentionally broad to capture enough descriptive information about what the general planetarium material is without getting prohibitively nuanced. In the development of PLUS 1.0, we did not provide formal definitions of each subject category (Table IV), opting to let our respondents interpret each subject as they saw fit. In PLUS 2.0, we have reformatted this question by providing a "definition though description" of each category by providing a list of topical examples of each subject. Further description of the revisions to PLUS can be found below in "Improvements to PLUS (Sec. IV E 1)." "Discipline(s)" will refer to the smaller subcategories of each subject listed along the left-hand axis in Fig 4. As partitions of the overarching subject, the discipline data allow for a more focused measure of what material each subject is dedicating instruction to in a planetarium environment.

Statistical measures of the responses to Q2.3 can be seen in Table IV. The mean, standard deviation, median, mode, and range are all measured in number of students. Astronomical sciences is the most numerous subject being instructed; however, noteworthy counts appear in all remaining subject categories. As seen in Table IV, the statistical measures of these data suggest a typical planetarium class between 20 and 40 students (median counts). We have chosen to use the median here as opposed to the mean due to 
TABLE IV. Statistical measures of the data for survey question Q2.3 asking how many students are in a typical class for each subject. The mean, standard deviation, median, mode(s), and range are measured in number of students. Standard counting error $\left(\sigma_{k}=\sqrt{N_{k}}\right)$ is assumed for each count bin. Values of the means and associated standard deviations imply non-normally distributed numbers of students—-median counts are a more representative measure of class size.

\begin{tabular}{lcccccc}
\hline \hline & & Mean & Standard deviation & Median & Mode & Range \\
\cline { 3 - 7 } Subject & Response counts & & (Number of students taught in typical class) & \\
\hline Astronomical sciences & 72 & 47 & 30 & 40 & 30 & 165 \\
Earth sciences & 31 & 46 & 32 & 30 & 25 & 130 \\
Physical sciences and engineering & 18 & 35 & 14 & 28 & 25 & 40 \\
Life and social sciences & 15 & 31 & 10 & 28 & 22 & 38 \\
Fine and performing arts & 9 & 28 & 14 & 24 & 24 and 30 & 48 \\
\hline \hline
\end{tabular}

the handful of comparatively large student classes in the astronomical sciences and Earth sciences subject categories as the median is a more robust measure against outliers, exemplified in the large range of values for those subjects.

Responses concerning the disciplines are presented in Fig. 4. The overarching subjects are presented in the legend; the numbers adjoining the subjects are the number of responses for each group. The disciplines for all subjects are defined down the left-hand axis in Fig. 4-the disciplines are color coded according to their respective subject presented in the legend. The percentages next to each bar are that discipline's contribution to the entire subject's available responses. For example, of the 32 respondents who selected the subject "Earth Sciences" as an instructed subject, 24 of these $(\sim 75 \%)$ chose "Geology" as a specific discipline instructed in their planetariums. As respondents were allowed to pick as many of the predefined disciplines as they desired, the percentages will not sum to $100 \%$. We also note a small discrepancy between the numbers of responses for the academic subjects shown in Table IV and Fig. 4. This discrepancy is due to the survey engine not requiring a respondent to supply a seat count while answering Q2.3they needed only select a subject(s) to continue with the survey, but could have left the seat count blank. The data shown in Table IV are only for respondents who selected a subject and provided a seat count.

These data provide more clarity as to how planetariums are being used from the standpoint of academic subject matter. Specifically, planetariums overwhelmingly report instructing general astronomy as the subject material in question-98.7\% of respondents to this question selected "general astronomy" as a discipline instructed in their planetarium. We stress to the reader that material which does or does not qualify as being "general astronomy" is still poorly agreed upon by the astronomy community and

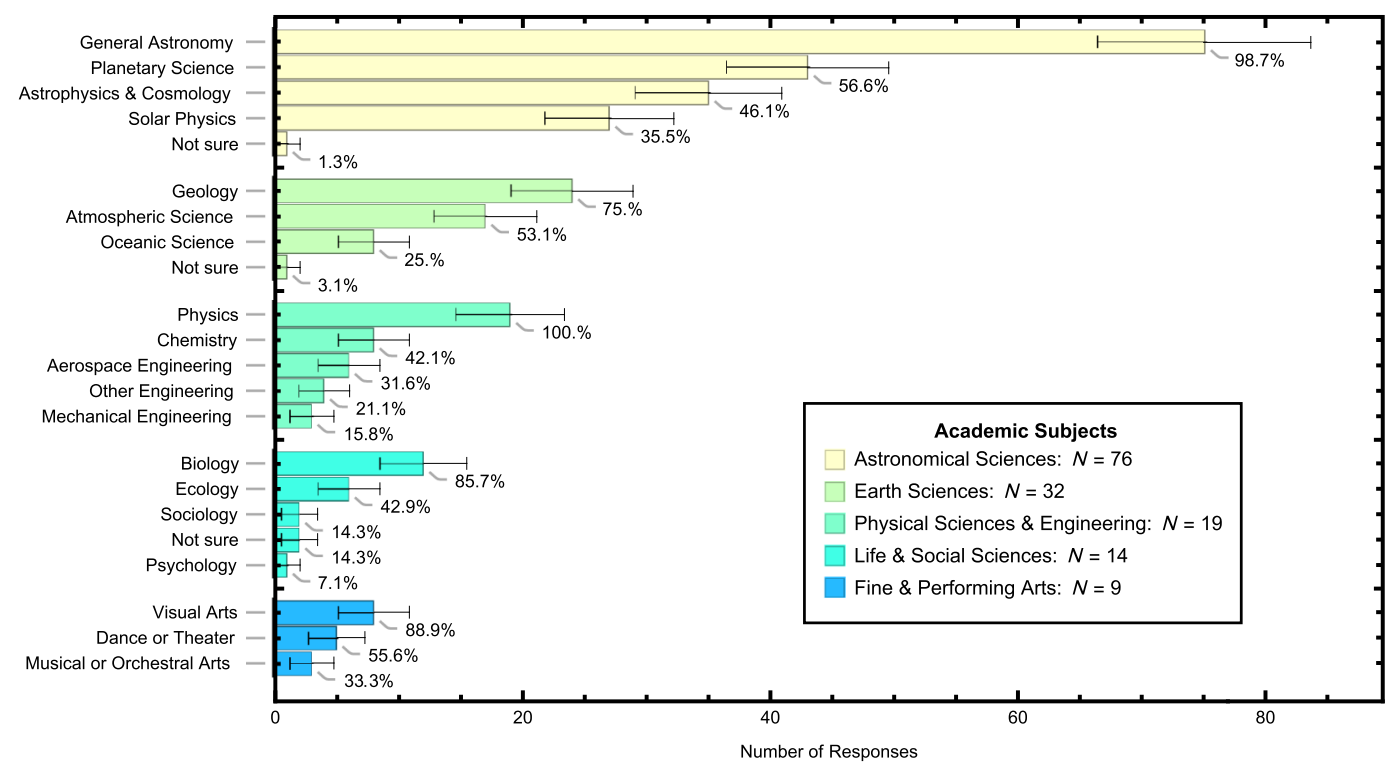

FIG. 4. Responses to Q2.3a-f concerning which academic disciplines (left-hand axis) are taught in a planetarium environment in each overarching subject (legend). Standard counting error $\left(\sigma_{k}=\sqrt{N_{k}}\right)$ is assumed for each data bin. Data are labeled with their respective percentage of the available response pool (corresponding " $N$ " values in legend); the number of available responses per subject is specified in the legend. Noteworthy counts are seen across all the sciences, not just astronomy. 


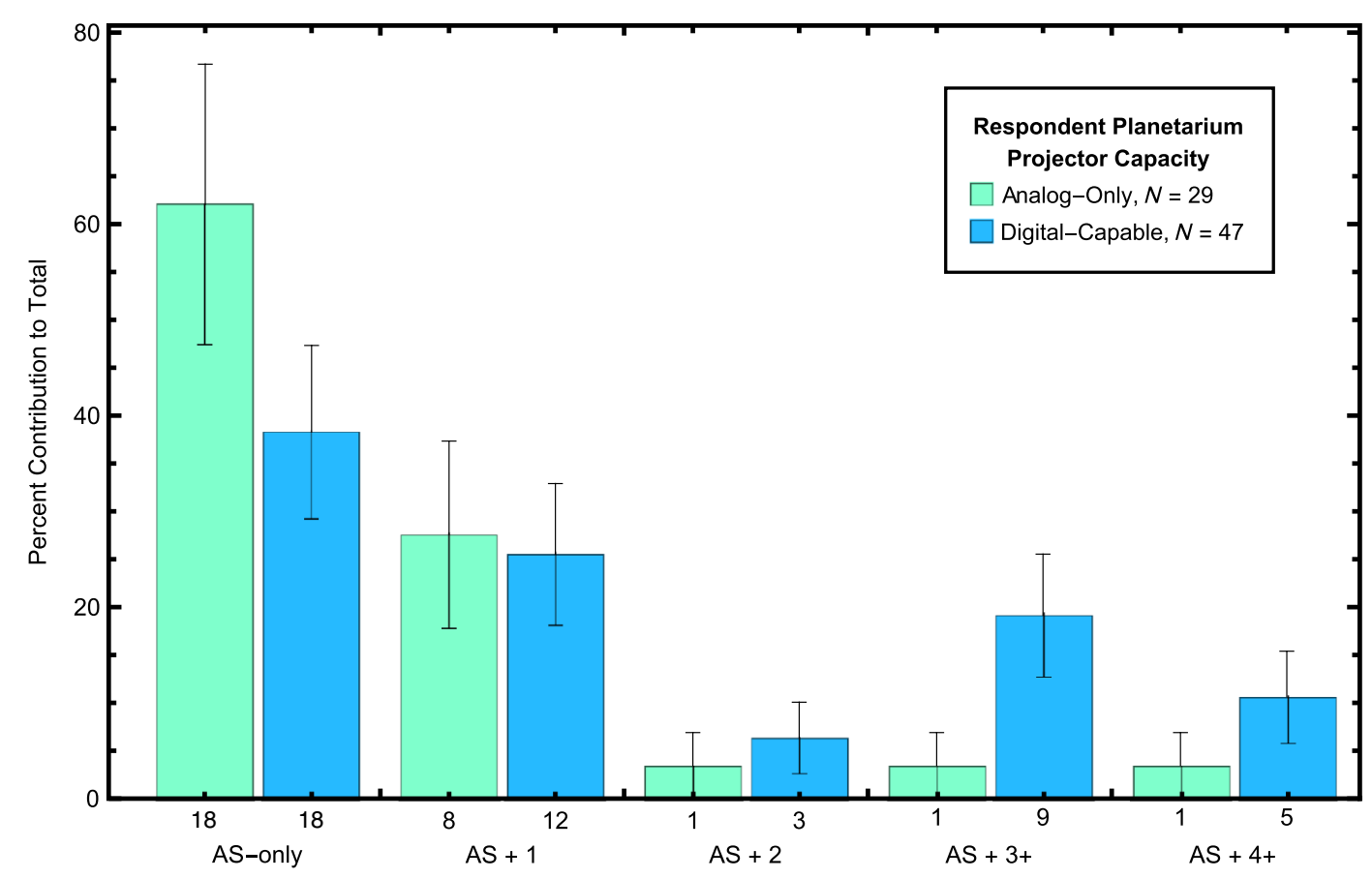

FIG. 5. Responses to Q2.3, collected into "astronomy only" (AS-only) and "astronomy plus" (AS + N) bins, based on respondent selections of "Astronomical Sciences" and any other $N$ subject(s). Responses have been further binned according to respondent planetarium projector capacity and expressed as their percent-equivalent values. Standard counting error $\left(\sigma_{k}=\sqrt{N_{k}}\right)$ is assumed for each data bin-raw counts for each bin are listed along the horizontal axis beneath each column.

no prompt was provided to the respondents as to what they should consider as being "general astronomy." We have omitted this terminology from the revised PLUS 2.0, opting instead to offer specific examples of astronomical subject matter. For this study, we will consider "general astronomy" to be a loose category of material that includes topics like sky motions, lunar phases, constellations, seasons, and naked-eye observations. We would also like to note that many studies in the past that concern planetarium learning have their topical focus within this category $[3,37]$. The data for the remaining subjects suggest that material shown to students in a planetarium not under the umbrella of astronomy would likely belong to one of the natural sciences like Earth or physical sciences.

Further context is gained by binning the response data in Q2.3 into "astronomy-only" and "astronomy-plus" categories. Responses have been grouped based on the number of additional subjects selected in Q2.3 along with "Astronomical Sciences." Additionally, responses have been split according to the projector capabilities of each planetarium (legend, Fig. 5), as determined through crossreferencing with secondary data from the IPS catalog. "Analog-Only" is assigned to respondents whose catalog entries contained only a star projector; "Digital-Capable" is assigned to respondents whose catalog entries contained at least one digital fulldome projector. A single respondent who did not select "Astronomical Sciences" as an instructed subject has been omitted from this binning scheme. These binned responses are shown in Fig. 5, with the binning groups denoted along the horizontal axis-bars measure each group's percent contribution to their projector group. For these binned data, "AS-only" corresponds to "Astronomical Sciences Only" and "AS + N" corresponds to the group of "Astronomical Sciences $+\mathrm{N}$," where "N" is the number of additional subjects. Respondents who selected four or more additional subjects have been grouped into one bin ("AS + 4+"). The number of true counts is listed along the horizontal axis beneath each column. The binning procedure described above was also performed on the counts from Q2.1 and Q2.2, but no distinction between the two projector groups could be drawn and have been excluded from this paper.

No reliable difference between analog-only and digitalcapable planetariums is measured across the entire set of binning groups (Fig. 5); however, we do note the measurably higher percent-equivalent counts for analog-only planetariums in the AS-only group and for digital-capable planetariums in the AS +3 group. Analog-Only planetariums do show a sharp decline in the reported number of additional subjects after AS-only, but digital-capable theaters maintain a shallower decline as the number of additional subjects increases. Additionally, for both projector groups most of the contributions to the instructed subjects are in the first two sets of columns (AS-only and AS +1) -Analog-Only planetariums contribute $89.1 \%$ and Digital-Capable planetariums contribute $63.8 \%$ of their respective responses to 
just these two. We also note here that PLUS respondents' planetarium projector capacities show a measurable preference towards Digital-Capable planetariums (29 AnalogOnly compared to 47 Digital-Capable).

Viewing these data through a practical technology lens, the sharp decrease in Analog-Only counts beyond AS-only is expected-an analog star projector can only project points of light, so its ability to show other visualizations may be severely diminished. Digital-Capable planetariums do not share this technological barrier, and could be expected to exercise subject presentations outside astronomy more easily. However, at least 13 AnalogOnly planetariums indicated they were able to use their planetariums for more than just astronomy. We conclude from these data that undergraduate students are going to planetariums to receive astronomy instruction but said planetariums are not definitively "astronomy-only" institutions. Furthermore, Analog-Only planetariums might suffer from a technological barrier against the presentation of other subject matter outside astronomy.

\section{Construct 3: Interactivity strategies and perceived environmental traits}

Our third research construct focuses around the planetarium as a physical learning environment and how the traits of that space impact instruction. We approached this by analyzing two survey questions (Q3.1 and Q3.2) and with interview discussions centered around respondents' opinions of the planetarium environment.

Q3.1: "Which, if any, interactive technologies are installed in your planetarium?"'

Q3.2: "Please rate the approximate usage of your planetarium's interactive technology by instructors using your dome during a typical class period."

Data for Q3.1 and Q3.2 have been shown together in Table V. Q3.1's original text allowed for respondents to pick individual types of technology from the following list:

TABLE V. Response counts to survey questions Q3.1 and Q3.2. Respondents were asked to rate how often interactive technologies like iClickers are used in their planetariums. Standard counting error $\left(\sigma_{k}=\sqrt{N_{k}}\right)$ is assumed for each response bin. Counts strongly suggest an overwhelming lack of interactive technology use in planetariums, but those that have interactive technology do use them with some regularity.

\begin{tabular}{lcc}
\hline \hline Use frequency & Response counts & Percent equivalent \\
\hline None & 62 & $80.5 \%$ \\
Never & 1 & $1.3 \%$ \\
Rarely & 4 & $5.2 \%$ \\
Intermittently & 6 & $7.8 \%$ \\
Reliably & 3 & $3.9 \%$ \\
Heavily & 1 & $1.3 \%$ \\
Total & 77 & $100 \%$ \\
\hline \hline
\end{tabular}

"none," "iClicker or similar individual remote device," "armchair-embedded remote," "cell phone application," and "other" (filled in by the individual respondent). If a respondent picked any option except for "none," they were then asked to qualify their answer with Q3.2, which presented the following options as selections: "neverthese systems are not used by instructors," "rarely-maybe once during a typical class," "intermittently-a few times during a typical class," "reliably_many times during a typical class," and "heavily—class cannot proceed without these technologies."

Only 15 ( $19 \%)$ of Q3.1's 77 respondents reported using interactive technology of any kind. No respondent offered their own "other" option. Of the 15 respondents who reported having interactive technology in their facilities, $14(\sim 93 \%)$ chose "iClicker or similar individual remote device," 3 (20\%) chose "cell phone application," and 1 ( $6 \%)$ chose "armchair-embedded remote." The spread of use frequency of these 15 can be found in Table V. The spread in usage frequencies is nearly symmetric around the "center" of the data ("intermittent" row), but due to the low number of counts for the five frequency ratings and corresponding uncertainties, we may only reasonably infer that planetariums equipped with some piece of interactive technology use said technology. We will discuss the implications of the large number of "none" counts below in the interview discussions.

IQ: Does your planetarium have an audience response system (ARS)? How often do instructors use it? If not, why and what do you see as the barriers to adding one?

IQ: Would you consider an ARS as a necessary component to produce a more interactive learning environment in your planetarium?

IQ: Why do you think a planetarium would or would not rely on an ARS?

When asked if their planetarium has an audience response system (ARS), eight of the $11(\sim 72 \%)$ interviews stated "No," and three of the 11 ( 28\%) stated "Yes." These responses trends are in fair agreement with the survey responses displayed in Table $\mathrm{V}$, if one considers all response groups excluding "No Interactive Tech" together. For the three respondents who possess an ARS in their planetarium, the descriptions of "daily," "commonplace," and "by almost every instructor" offer a positive, if illdefined picture of how often such systems are used in a planetarium when available.

When asked if they view an ARS as necessary, three of the $11(\sim 28 \%)$ stated that such a system was necessary, three of the $11(\sim 28 \%)$ stated that such a system was not necessary, and five of the $11(\sim 44 \%)$ stated that such a system is not necessary but possibly useful. All respondents, regardless of their personal facility's use or attitude toward an ARS, were asked to consider why a planetarium would or would not rely on one. Six of the $11(\sim 55 \%)$ 
respondents suggested that an ARS is not appropriate for a planetarium environment. The reasons provided by the interviewees to explain these opinions include the following: not having enough students in the theater to warrant such a system, using other means of interactive learning like Q\&A's, group discussions, and peer-to-peer instruction, and the use of "zero-tech" interactive technology like show of hands and four-letter "ABCD" multiple-choice cards.

Dr. Blue: "Our classes will have maybe 25 to 30 people in them. If I' $m$ in there with one of my intro classes where I've got 25 students, and I know them all, I'm interacting with them anyway. I can call them by name and ask them questions. I don't need clickers."

Professor Orange: “...it's efficient and accessible, but it's certainly not a necessity. Well, probably my guess is that if you use some sort of response system, it does pull you out of the visuals for a moment. That's not a super accessible way for some people to learn and respond. So you put up a visual and then in a way that removes you from that immersive space for a moment. I think there might even still be a tendency that even if you know about the research that active learning leads to better retention and things like that, that you feel like this space is impactful enough that maybe it'll do it on its own...."

Respondents that favored an ARS spoke confidently of its utility to those courses that use it, while respondents who did not favor an ARS were equally confident in their interactive strategies that did not use one. This mix of response trends suggests that ARS utility, which has demonstrated instructional benefits in the interactive classroom environment [21,23-25], may still require further dedicated exploration specifically in promoting interactive planetarium environments.

IQ: Which traits about your planetarium do you think make it beneficial to the instruction of the astronomy disciplines? Why do you think this is the case?

IQ: Which traits about your planetarium do you think might make it useful to the instructions of disciplines outside of astronomy? Why do you think this is the case?

All of the responses to these questions were variations on the same theme-visualizations. Subjects considered this theme as the most beneficial trait their planetariums possess, satisfying both affective and cognitive classroom outcomes. Subjects highlighted the planetarium's visualizations as promoting interest in astronomy and positive student attitudes to learning through displays of the flashy "wow factor" visuals (principally affective outcomes). Subjects equally stressed the planetarium's ability as an instructional instrument by displaying detailed depictions of large scale structures and motions in two and three dimensions (principally cognitive outcomes). This simultaneous satisfaction of both classroom outcome types mirrors the audience content goals of informal planetarium professionals explored by Plummer and Small [38], which showed no particular preference between the goals "interest/engage" and "education about content" for any particular audience type.

Dr. White: "We spend a lot of time sharing pretty pictures in astronomy, and the planetarium is a great way to bridge the gap between reality-here's the horizon, here's stuff moving across the sky... and where the pretty pictures come from. ...So I think planetarium is great for giving context..."

Dr. Violet: "The planetarium exemplifies or animates what's in a book and it makes it come more alive for them. Since they can see things actually moving above them, then what they're reading makes more sense to them."

Dr. Red: "It's an immersive visual experience so that the dome essentially fills the field of view, so it's able to convey scale and proportion and directionality in a way that a figure on a printed page just doesn't do."

When asked to consider traits that could benefit disciplines outside astronomy, the nine respondents whose planetariums were digital capable converged upon the same theme of visualizations. These respondents also saw both affective and cognitive potential in a planetarium environment, similar to their reasoning for astronomy; these responses align with work by Sumners et al. [7], which highlighted the capacity of a portable digital planetarium to instruct Earth and space science concepts. Our two analog-only respondents did not speculate upon the possible benefits to nonastronomical disciplines, making this question the only one in this study without substantive input from analog-only planetarium representatives.

Dr. Brown: "It's a great space to have poetry readings, or banned book readings or things like that, because you can have somebody up there with a podium and we can put the software that we have that runs our planetarium. We can also put other content on the dome, we can put any video that we want up on the dome, which is really important... [all of the above] just takes a little bit more work to create that content."

Dr. Red: “...a visually immersive show, and so it's different than something that they can just see on a classroom screen... it's also a way just to break up the pace of the class and bring the students to a different environment to maybe jog them out of old habits and get them thinking... we can make these connections in different ways, not only between disciplines, but also across the college-all of these disciplines have something to say to each other."

These responses imply a deeper benefit across the various subject matters: scaffolding for students to better comprehend perspective, size, and scale. Past research has shown that these skills can be difficult for learners [39], but spatial comprehension, once learned, may correlate with student achievement [40,41]. The use of electronic media during instruction, much like those found in a planetarium theater, has been shown to provoke greater student understanding [42] and to dissolve misconceptions [43]. Continued efforts to describe, measure, and refine this 
scaffolding should be undertaken for the instruction of undergraduates, especially those studying the sciences and engineering $[4,40,44]$.

The response trends stressing both content and attitude goals are consistent with the analysis made by Small and Plummer [30] and Plummer and Small [38]. Furthermore, our interview respondents' thoughts on other, nonastronomical subject materials being presented in a planetarium theater showed less apparent skepticism than was expressed in Croft [15]; however, we note that our interview respondents for this particular point uniquely operated digitalcapable theaters. Arrayed with this study's survey data (Table IV and Figs. 4 and 5), we propose that the same visualization capacities that have long promoted the use of planetariums for undergraduate astronomy education $[5,14]$ could also benefit other collegiate subject matters in the same planetarium environment [7].

IQ: Which traits do you see as detrimental to instruction in a planetarium?

Subjects were also asked to consider what traits they see as impediments to instruction in the planetarium environment. Unsurprisingly, the trait deemed as an impediment was inherent to the very idea of a planetarium theater: darkness.

Dr. White: "...when I have undergraduates in there I have to be careful as I bring up the lights to say, 'Okay, wake up the person next to you,' because for better or for worse people fall asleep when you turn out the lights and start talking. It's kind of ironic because, as I said, I do a lot of school groups, and when these same people are in fourth or fifth grade I can't shut them up....then they come here again in 14th to 15th grade ten years later and they're falling asleep."

Dr. Red: “...we also of course get the students that were working late or studying late the previous night, and they're now in a darkened room with comfy seats, and we'll have some students actually nod off, simply because the environment is conducive to napping. ...the darkened environment isn't necessarily the best learning environment, but it is part and parcel of the technology of portraying the imagery on the dome."

Numerous studies have measured the benefits of the planetarium [1,3], but to our knowledge none have specifically explored how a planetarium's darkness may impact learning. We will accept the darkened environment as existentially necessary to the operation of a formal planetarium environment, and exploration of if or how lighting conditions impact planetarium learning warrants further investigation.

\section{Construct 4: The nature of presented content}

Our last research construct seeks to confront the nature of content presented in planetariums. We approached this construct primarily with three survey questions (Q4.1, $\mathrm{Q} 2.4$, and Q2.5) and interview discussions.
Q4.1: "Which of the following selections describes the content your facility uses?"

Response data for Q4.1 is shown in Fig. 6. For each content style (listed across the horizontal axis), respondents were asked to specify whether they or a different facility produced that style of content used in their planetarium (Fig. 6, legend). Respondents could select as many choices as possible, including an "Other" option for individualized responses. The number of respondents who had information to offer for each content style is specified along the horizontal axis under the corresponding content type. The percentage labels next to each bar denote that bar's contribution to that content style's total number of responses. The first three sets of bars are of greatest importance to this study as these three groups are structurally compatible with the learning process and learning environment corners of our conceptual framework. The last three sets of bars were asked for the sake of categorical completeness, but did not advance our investigations substantially and will not be discussed further.

The data show a robust trend among the first three content types. Respondents to Q4.1 show overwhelming preference for live content being produced locally, by their facility, regardless of whether or not the content was presented specifically to students or the general public. Conversely, prerecorded video (PRV) content shows an overwhelming preference for content produced by other facilities. These data thus contend that planetariums may show near-complete preference for making their own content if they themselves are responsible for conveying it to their audience through a talk, lecture, or presentation. However, these data equally contend that if content is presented by "pressing "play," like a video, planetariums are more likely to source that content from an outside producer. These trends will be expressly explored during the interview discussions below.

Q2.4: "Describe the topics, astronomical or otherwise, which you find are best or most effectively instructed in planetariums."

Q2.5: "Describe the misconceptions, astronomical or otherwise, which you find are being taught or potentially reinforced during instruction in planetariums."

The responses to these questions were analyzed using an iterative coding technique. In this technique, responses were read and given alpha-numeric code tags that described the constructs emergent from the data. These constructs were not predefined, so the group of responses was analyzed in successive sets of 10 , with codes being created, merged, or destroyed as needed until the entire set of responses was analyzed. A final period of code merging was done on the complete dataset to reduce the number of minimally descriptive or obsolete codes. Response codes were then counted and the resulting distributions interpreted. The resulting coding scheme can be seen in Table VI. General code themes are in the left-hand 


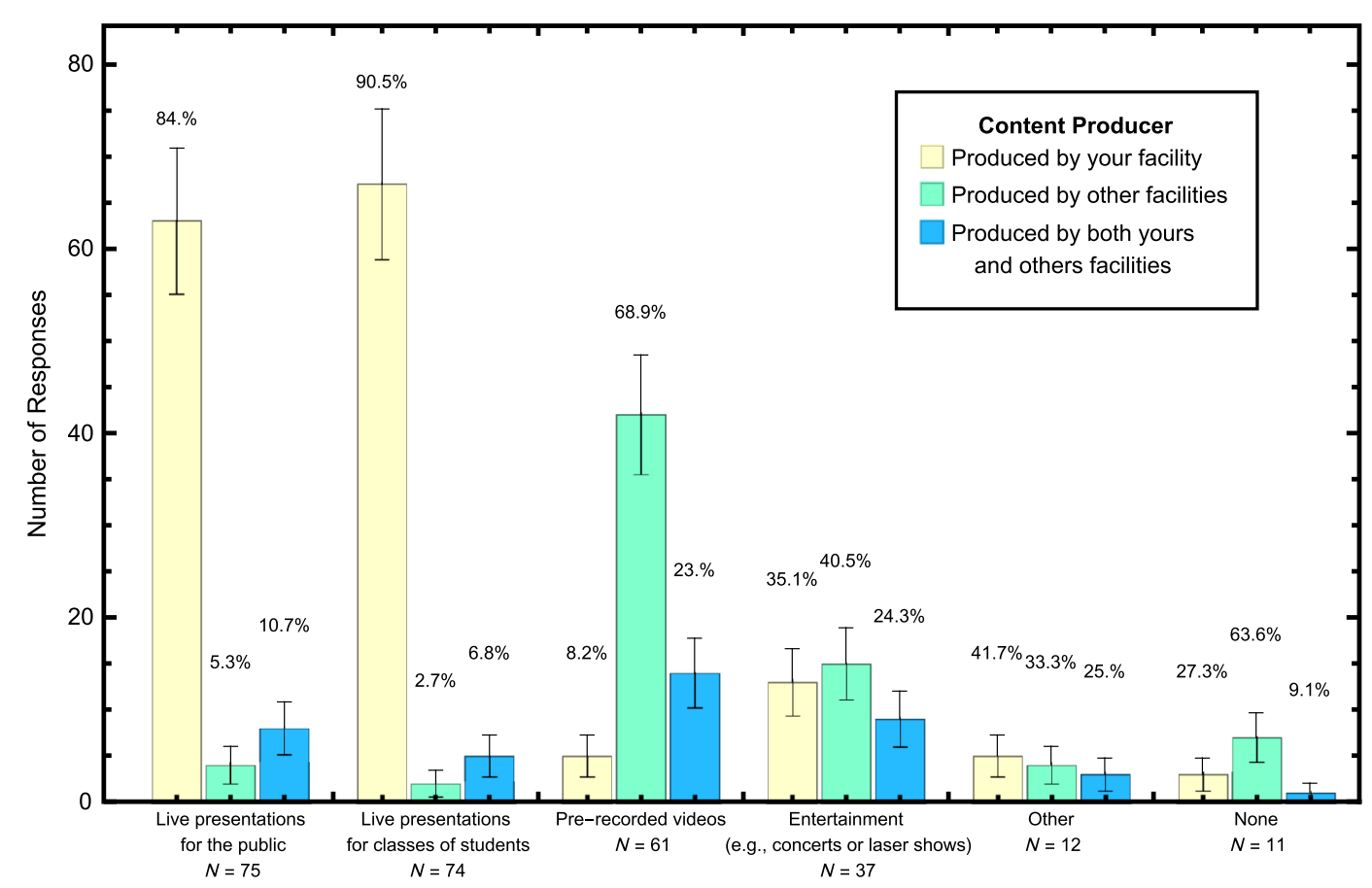

FIG. 6. Responses to Q4.1 concerning what content types are used by planetariums and what entity produced said content. Percentage labels show each data count's contribution to the entire content type; the number of respondents for each content type is specified underneath each content type along the horizontal axis. Standard counting error $\left(\sigma_{k}=\sqrt{N_{k}}\right)$ is assumed for each data bin. Data propose that live presentations are more prevalent than any prerecorded material, and that a planetarium is more likely to make their own live material and have someone else make their prerecorded video content.

columns with more specific subcodes and their descriptions in the adjoining center columns - the total number of responses qualifying for each general theme is also found in the left-hand column. Each subcode's contribution to its general code theme is expressed in the right-hand column. We have omitted the inclusion of the following subcodes which contributed $10 \%$ or less to their general code themes or had only a single count: A3 (geographic

TABLE VI. Descriptive codes for survey question Q2.4. Response codes are sorted by general category in the left-hand column-the number of qualifying responses are adjoining. Descriptions of each subcode are in the center right-hand column. Counts for each subgroup and their respective percentage of their code category are in the right-hand column.

\begin{tabular}{|c|c|c|c|}
\hline General code & Subcode & Description & Contribution to code \\
\hline General astronomy (A), $N=54$ & $\begin{array}{l}\text { A1 } \\
\text { A2 } \\
\text { A4 } \\
\text { A5 } \\
\text { A6 }\end{array}$ & $\begin{array}{l}\text { Sky motions (rise or set, retrograde motion); celestial sphere } \\
\text { Lunar phases } \\
\text { Constellations } \\
\text { Seasons } \\
\text { Sky coordinates (local, celestial, ecliptic systems) }\end{array}$ & $\begin{array}{l}42(77.8 \%) \\
20(37.0 \%) \\
19(35.2 \%) \\
19(35.2 \%) \\
21(38.9 \%)\end{array}$ \\
\hline $\begin{array}{l}\text { Spatial or temporal } \\
\quad \text { recognition (B), } N=10\end{array}$ & $\begin{array}{l}\mathrm{B} 1 \\
\mathrm{~B} 2\end{array}$ & $\begin{array}{l}\text { Sizes, distances, and/or scales (time and space included) } \\
2 \mathrm{D} \text { or } 3 \mathrm{D} \text { orientations }\end{array}$ & $\begin{array}{l}9(90.0 \%) \\
2(20.0 \%)\end{array}$ \\
\hline Astrophysics (C), $N=19$ & $\begin{array}{l}\mathrm{C} 1 \\
\mathrm{C} 2 \\
\mathrm{C} 3 \\
\mathrm{C} 4\end{array}$ & $\begin{array}{l}\text { Compact objects (any) } \\
\text { Gravity (Newtonian, relativistic) } \\
\text { Stellar evolution } \\
\text { Galactic and universal structure(s) (cosmology and } \\
\text { cosmic microwave background included) } \\
\text { Orbital mechanics }\end{array}$ & $\begin{array}{l}4(21.1 \%) \\
4(21.1 \%) \\
3(15.8 \%) \\
12(63.2 \%) \\
3(15.8 \%)\end{array}$ \\
\hline Planetary science (D), $N=10$ & $\begin{array}{l}\text { D1 } \\
\text { D2 } \\
\text { D4 }\end{array}$ & $\begin{array}{l}\text { Comparative planetology } \\
\text { Surfaces and interiors } \\
\text { Minor bodies }\end{array}$ & $\begin{array}{l}2(20.0 \%) \\
6(60.0 \%) \\
2(20.0 \%)\end{array}$ \\
\hline Ancient astronomy (E), $N=9$ & $\begin{array}{l}\text { E1 } \\
\text { E2 }\end{array}$ & $\begin{array}{l}\text { Historical interests } \\
\text { Navigation }\end{array}$ & $\begin{array}{l}3(33.3 \%) \\
6(66.7 \%)\end{array}$ \\
\hline
\end{tabular}


effects), D3 (exoplanets), D5 (planetary systems), and E3 (timekeeping).

These data immediately oblige the ability of a planetarium to render immersive environments. Codes A1, A2, A5, A6, and C4 directly correspond to topical material that benefits from a full field-of-view projection or 3D "flying" simulation. Moreover, these five code groups map almost identically to the astronomical misconceptions held by undergraduate learners categorized by Zeilik et al. [11], bolstering the planetarium as an environment well suited to confront these $[4,5,14]$. This communal leaning toward topics benefiting from a planetarium's projection capacities will be discussed further in the interview discussion below. We also note here the relatively low tally of content that, while still in the academic domain of astronomy, does not appear to be held at the same level of "planetarium-worthy" content. For example, four of the five subcodes in code group C (astrophysics) do not break a group fraction of $50 \%$-the sole exception is $\mathrm{C} 4$ ["galactic and Universal structure(s)"']. At this time, we are uncertain if these code distributions imply a lack of planetarium content availability, knowledge, or interest.

Challenges arose when attempting to code the responses to Q2.5, regarding possible misconceptions being taught or reinforced in a planetairum. Overall response counts significantly lower than Q2.4 and overall response quality and phrasing immediately implied that most respondents did not understand the question. Responses to Q2.5 were mapped to the code groups established in Q2.4 where possible, but additional codes pertinent to Q2.5 were innovated where necessary. Codes A1, A4, B1, X (references misconceptions held before planetarium visit), and $\mathrm{Y}$ (blank or rebuking answer) were the only codes to measure more than four counts $(13,4,6,4$, and 12 , respectively). After reflecting upon the responses from Q2.4 and Q2.5, we decided to avoid such open-ended question items in PLUS 2.0, discussed below.

We will expound upon some of the themes within the groups A1, A4, and B1 that respondents presented. Many of the stated misconceptions in A1 centered upon the nature of the celestial sphere, and how as a model of the sky it may reinforce the idea that all objects in the sky are the same distance away or do not otherwise change position. Themes in A4 focused upon potentially confusing aspects about constellations. Since a projector can be switched on and off (unlike actual stars), learners may become confused when a particular constellation or star field is shown on a certain spot on the dome, the projector is switched off and changed to another star field, and then turned back on with the new field on the same spot on the ceiling as the old one. This might lead to a misconception that constellations may be able to overlay one another or that the position of stars in the sky is entirely fluid and can be changed. Misconceptions surrounding B1 centered on the planetarium's ability to give a false sense of temporal and spatial scales. For example, a planetarium may simulate flying through several mega-light-years of space in a few seconds (well in excess of light speed). For content experts, this flying is obviously exaggerated, and experts have been shown to mentally jump between various size scales easily [45]. Such exaggerated displays might not be obvious to content learners who have been shown to hold intrinsically distorted conceptions of both temporal and spatial scales $[11,39,40,46]$, and may need more contextual support when experiencing scales well beyond their day-to-day experience [45]. These distortions, if left without appropriate confrontation and correction $[47,48]$, could damage learners' understanding of these materials and undercut the use of a planetarium as a learning environment.

IQ: Benefits and drawbacks to live and prerecorded video content styles

To investigate the dichotomy between live and prerecorded content styles emergent from the survey data (Fig. 6), respondents were asked to consider the benefits and drawbacks of each of the content styles in a planetarium learning environment. We summarize the responses in Table VII. We also note here that two of this study's interview respondents did not possess the projector capacity to show prerecorded video content in their planetariums. We stress to the reader that we are considering each of the two content styles below as pure styles. We understand that the two may be combined with other one another for instructional or presentation purposes [30], but for the following discussions we will address each style as a "pure" mode of content presentation.

In regards to the benefits of live presentations, all 11 respondents described variations on the same underlying theme-live presentations have a human aspect that other

TABLE VII. Summary of interview responses concerning the benefits and drawbacks of the pure content styles explored by survey Q4.1. PRV: pre-recorded video.

\begin{tabular}{lcc}
\hline \hline $\begin{array}{l}\text { Content } \\
\text { type }\end{array}$ & \multicolumn{1}{c}{ Benefits } & Drawbacks \\
\hline Live & $\begin{array}{c}\text { Instantly adaptable to } \\
\text { audience. } \\
\text { Content can be changed } \\
\text { instantly. }\end{array}$ & $\begin{array}{c}\text { Needs informed presenter } \\
\text { or content expert. } \\
\text { Presenter or audience may } \\
\text { get distracted. }\end{array}$ \\
& $\begin{array}{c}\text { Interpersonal engagement } \\
\text { with audience. }\end{array}$ & $\begin{array}{c}\text { Additional technical } \\
\text { expertise required. }\end{array}$ \\
PRV & $\begin{array}{c}\text { Reliable and reusable } \\
\text { content package. }\end{array}$ & $\begin{array}{c}\text { No interpersonal } \\
\text { engagement. }\end{array}$ \\
& $\begin{array}{c}\text { Well-defined content and } \\
\text { duration. }\end{array}$ & $\begin{array}{c}\text { Audiences are mostly } \\
\text { passive. }\end{array}$ \\
& High production value. & Questions must be held \\
& "Press 'Play"” ease & until finished. \\
& of use. & Expensive to produce \\
& & and acquire. \\
\hline \hline
\end{tabular}


content styles simply do not. A live presenter has a level of interactivity and adaptability that cannot be replicatedthey are "there" with their audience in the moment they are learning. Questions from the audience can be fielded immediately, allowing for misconceptions to be confronted as they emerge. Live presenters can engage with their audience, adapting or altering their presentation as audience members provide feedback-additionally, live presentations can be guided by the audience members themselves, the live presenter serving more as a learning facilitator than a content presenter.

When discussing the drawbacks of live presentations, responses complimented the benefits described above. A live speaker holding a presentation needs to be informed about the presented content-experience in public speaking is beneficial, but if a speaker does not possess the content knowledge necessary to instruct the audience, learning could suffer. Live presenters may also get sidetracked as questions from the audience divert the discussion away from the established lesson goal. While a learner guided discussion does have its benefits, we contend that such an impromptu diversion in an uncommon learning environment like a planetarium theater could be considered a drawback, at least for formal learning environments. Finally, live presenters may require a second person with the technical expertise needed to operate the planetarium, as it is not guaranteed that an instructor at a particular college or university has the expertise necessary to operate a planetarium's systems.

Concerning the benefits of PRV content, most respondents saw the production value as its greatest benefit. Video content is typically of a higher visual caliber than any live presentation concerning the same material, and such visuals are of a definite duration and content depth. Videos do not change between presentations and are usually easy to use for a presenter, requiring little more than a "play" button, and are reliable resources for an instructor who knows exactly what they want to show their learners and how much time they want to spend. Finally, PRV content, having usually been made with the collaboration and input of research institutions and content experts, may be used as content presentation in the absence of having an actual expert. The famed Powers of Ten video highlights the utility of PRV content, delivering an effective instructional message with measurable increases in learner knowledge [49].

The discussed drawbacks for PRV content were centered on the lack of a human component that live presentations are built around. Video content does not interact with its audience, and such a presentation style renders an audience functionally passive, with little engagement beyond what the video itself is able to engender. Questions formulated by the audience need to wait until the end of the presentation, by which time they may fade or the audience loses interest. The last drawback noted by the respondents is cost. The high production quality of planetarium videos is typically accompanied by a high cost that some planetariums simply cannot afford.

A particular point was raised during the interviews that we are presently disinclined to categorize as either a benefit or drawback to PRV content: a planetarium with video projection capabilities is very similar to a movie theater environment, and learner groups may take behavioral cues from being in such an environment. This point was raised specifically in light of younger learners who comport themselves in a planetarium environment much the same way they would in a traditional movie theater space.

Dr. Yellow: "So when you have young kids they understand watching a movie? They're familiar with watching movies so it's just a little bit different format of a movie. I've had some really loud rambunctious groups of middle schoolers usually and when I'm talking they don't pay attention but as soon as you hit 'Play' they're quiet because they know, 'Oh, the movie's playing, we need to listen."

We note this here for this particular study because it raises the possibility that undergraduate planetarium learners might also comport themselves like their younger counterparts, eschewing their active learner tendencies like asking questions or discussing in favor of passive learner tendencies like watching and listening; however, further study is needed to confront this supposition.

The interview subjects also discussed some of the challenges and possible solutions to obtaining or creating new content, not just for astronomy, but for other subjects as well (Table IV and Fig. 4). The largest challenge or barrier against the wider use of planetariums was the availability of content. This challenge has both financial and existential facets: some planetariums are simply not able to afford the expense of certain content styles (like high production value PRVs), or content that is desired to be shown has not been innovated (fulldome presentations for biological content, for example). These interview responses partially oblige the data for Q2.4 (Table VI) by suggesting that topics like planetary science or ancient astronomies (code groups $\mathrm{D}$ and $\mathrm{E}$, respectively) could be more widely instructed in planetariums if the content was available.

These challenges echo the investigation undertaken by Fraknoi [29], in which instructors voiced challenges to the instruction of astronomy at nonresearch institutions, particularly community colleges. That study found a common, nonadministrative difficulty between its participants that we could describe as academic isolation. That study's participants voiced desires to ask other instructors for advice, to have time to innovate new materials for instruction, and to have a network of other instructors in similar situations who could coordinate or exchange strategies and materials [29]. We note these points here to highlight that the same difficulties for astronomy instructors may also translate to those attempting to use planetariums, and that 
the continued effort toward easier and streamlined access to planetarium educational materials should continue [12].

\section{E. Theoretical synthesis and future work}

We now address our findings in light of our theoretical framework, LEPO [27]. Collegiate planetarium learning occurs in a formal learning environment, which is characterized by darkened illumination conditions and immersive visualizations. These visualizations may be presented either live or as prerecorded video content, with each having perceived strengths and weaknesses as content styles (Table VII). Learning processes appear to unfold in a manner similar to a "typical" collegiate lecture setting, characterized by an instructor-centered information delivery dynamic. This procedural dynamic is likely not supported by commonplace classroom technologies like iClickers to promote student interaction and engagement (Table V). Learning outcomes seek to leverage the environment to the fullest, with visualization-based scaffolding for astronomical content being the principal outcome (Table VI), with outcomes outside the topical domain of astronomy being less common, but not negligible (Fig. 4).

Our continuing investigations will focus on cornering the learning process and learning outcomes in collegiate planetarium environments. We plan to conduct a small sample study using the validated observation protocol classroom observation protocol for undergraduate STEM [50] in the planetarium environment. This protocol has been demonstrated to measure undergraduate STEM classroom behaviors across a wide sample of lecture settings [51], and doing so in a planetarium would allow behavioral information to be gathered without the use of self-reporting instruments. Additionally, future iterations of PLUS (described below) will collect information descriptive of the broad learning process trends throughout the U.S.

\section{PLUS 2.0: Improvements and revisions to survey}

The results of this study have allowed us to implement a set of revisions to our original PLUS 1.0 instrument. Future distribution of the revised survey will further our goals of maintaining a contemporary measure of planetarium use for collegiate educational purposes. Here, we present our revisions for each of our original research constructs as well as emergent constructs.

New construct: Respondent characterization.-The use of the IPS catalog as a source of secondary data demonstrated a possible pitfall in future distributions of PLUS, specifically using data that may not be as up to date as possible or which may have missing entries. In light of this we have implemented changes to the opening section of PLUS. These changes ask respondents to provide their host institution's Carnegie classification from a shortened list of possible descriptions [31], to give the approximate population of their immediate surroundings (letting us provide context for learner populations), and to select a description of their planetarium's projector (giving us information for other constructs as well as tracking facilities' transitions to digital technology).

2. Construct 1: Learner population and use frequency.Questions probing this construct have been separated into individual questions to avoid the data collection difficulties with Qualtrics, described above. We have separated the original "K-12" learner population into "elementary (K-8)" and "high school (9-12)" populations, and provided definitions of each group for respondents to consider. Additionally, we have expanded the use-frequency question to explore learner populations as an entire group and as individual classes within that population.

In the college-specific portion of the survey, we have added two "select all that apply" questions for respondents to describe the type of undergraduate student coming to their planetarium and how learning commences in undergraduate classes from a list of descriptive archetypes. These archetypes have been crafted around discussions held during the PLUS 1.0 interviews in 2019 and will help establish a more accurate picture of which students are being instructed in planetarium environments and how that instruction takes place.

\section{Construct 2: Subject materials and projector-dependent} variety.-We have decided to simplify this section from the previous incarnation of PLUS. We have removed the freeresponse sections (Q2.4 and Q2.5 described above) entirely and removed the discipline follow-up questions. We have used our free-response analysis and subject or discipline question to restructure a single question asking respondents to select the subject material shown in their planetarium and how large a class learning that material is. Additional subject material categories and descriptions of each category have been added to provide more topical constraint to each category without becoming prohibitively nuanced with any particular definition. This information, coupled with our respondents' projector types, will allow further tracking of "astronomy-only" and "astronomy-plus" planetariums.

\section{Construct 3: Interactivity strategies and perceived} environmental traits. - We have revised our original question surrounding interactive strategies in college classes. The range of possible use frequencies for interactive technology has been simplified following our analysis of Q3.1. We have also defined other interactive technologies that we would like our respondents to consider-these additional definitions have been made following our interviews in 2019.

Respondents would be asked to describe how the interaction between instructors and planetarium staff unfolds during a college-level class, using a list of "select 
which best describes" options. These options will contrast the responsibilities for planetarium operation and content presentation between planetarium staff and instructors. This information, combined with that described under "construct 2," will also allow a more narrowed view of the learning process in planetarium environments.

5. Construct 4: Nature of presented content.-As is seen in Fig. 6, the dichotomy between locally produced live content and outside-sourced prerecorded content is stark, and our interview discussion (Table VII) highlights the reasons as to why. Barring some major shift in planetarium resource paradigms, we see greater value in probing our respondents further about what kind of content is used, rather than continued investigation of who is ultimately responsible for producing it. Thus, we have partially merged this aspect of construct 4 into construct 3, by integrating a more detailed list of content types into our question about technology usage. Combining this updated construct with the other three will further our understanding of the learning environment and the learning outcome of collegiate planetarium visits.

Additionally, we have added a question tasking our respondents to describe what kind of learning environment they have been asked to provide for our list of learner populations. We have chosen to provide brief descriptions of formal, informal, and entertainment environments for the survey takers to consider when answering this question $[10,12,16,26,36]$.

It is our intention to distribute this new survey pending institutional review board approval for human subjects research. This revised PLUS 2.0 has been included as Supplemental Material [52].

\section{CONCLUSIONS}

An initial study has been conducted to investigate the use of planetariums by undergraduate astronomy learners in the U.S. Responses to an online survey and follow-up interviews have been analyzed to establish trends among college-serving planetariums and to further develop the planetarium usage survey (PLUS) instrument.

Responses concerning audience populations (Fig. 2) propose that the primary learner group serviced by college and university planetariums is K-12 learners, not their own college learners. These higher counts of younger learner groups compared to college-level learners seem to rest upon curricular demand, as more K-12 instructors are requesting the use of a planetarium on a local college or university campus compared to that college's or university's instructors.

Survey data concerning audience populations (Fig. 2) and the follow-up interview responses strongly indicate that undergraduate astronomy learners in a planetarium environment are typically non-STEM major, novice science learners. These learners are being instructed in a planetarium to take advantage of the space's visual scaffolding capacity, with instructors using a planetarium's projection capabilities to produce an immersive learning environment. Learning outcomes expected of these learners may be either affective or cognitive, but no conclusive preference has been determined by this investigation. Instruction of these learners in a planetarium environment happens between once per week to once per month (Fig. 3); however, there is significant variation within that characteristic frequency range. An exception to these novice learner trends is for more experienced learners who are receiving training to teach future science learners-this group of planetarium learners is not using a planetarium to learn astronomy content, but rather to learn pedagogical approaches.

This study has shown that planetariums are not uniquely the domain of astronomy instruction and that other subject material, particularly the natural sciences closely aligned with astronomy (Table IV and Fig. 4), are instructed at the collegiate level in planetarium spaces. However, content most widely seen as well instructed in planetarium environments is within the field of astronomy, specifically the widely defined "general astronomy" (Table VI). Technology is a factor in how varied this subject material may be, with digital-capable planetariums reporting measurably more varied subject materials than their analog-only counterparts (Fig. 5). Content presented to planetarium learners favors live content, presented by an in-house speaker and produced at the presenting planetarium itself. Prerecorded content is used less widely than live content (Fig. 6) and is typically produced outside the planetarium using it. Regardless of style, content is often not being presented using the aid of an audience response system (ARS) (Table V). Instructors who do use an ARS are most commonly using an iClicker or similar remote-style system. Reliance toward or against using an ARS presently shows no definite theme. The continued development and distribution of a revised usage survey is planned for the future to further explore the planetarium as a collegiate learning environment.

\section{ACKNOWLEDGMENTS}

The authors would like to extend our thanks to the International Planetarium Society for the use of their database to invite participation in this study. We would also extend our deepest thanks to this study's survey and interview participants, as well as our two referees for the comments and guidance. Publication of this article was funded by the University of Colorado Boulder Libraries Open Access Fund. 
[1] B. D. Brazell and S. Espinoza, Meta-analysis of planetarium efficacy research, Astron. Educ. Rev. 1 (2009).

[2] A. Lelliott and M. Rollnick, Big ideas: A review of astronomy education research 1974-2008, Int. J. Sci. Educ. 32, 1771 (2010).

[3] T.F. Slater and C.B. Tatge, Research on Teaching Astronomy in the Planetarium (Springer Briefs in Astronomy, 2017), ISBN 978-3-319-57202-4.

[4] K. C. Yu, K. Sahami, V. Sahami, and L. C. Sessions, Using a digital planetarium for teaching seasons to undergraduates, J. Astron. Earth Sci. Educ. 2, 33 (2015).

[5] K. C. Yu, K. Sahami, and J. Dove, Learning about the scale of the solar system using digital planetarium visualizations, Am. J. Phys. 85, 550 (2017).

[6] A. Lelliott, The concept of spatial scale in astronomy addressed by an informal learning environment, African J. Res. Math. 14, 20 (2010).

[7] C. Sumners, P. Reiff, and W. Weber, Learning in an immersive digital theater, Adv. Space Res. 42, 1848 (2008).

[8] L. Carsten-Connor, A. M. Larson, J. Arseneau, and R. R. Herrick, Elementary student knowledge gains in the digital portable planetarium, J. Astron. Earth Sci. Educ. 2, 65 (2015).

[9] J. D. Plummer, A. Kocareli, and C. Slagle, Learning to explain astronomy across moving frames of reference: Exploring the role of classroom and planetarium-based instructional contexts, Int. J. Sci. Educ. 36, 1083 (2014).

[10] K. Yu, Digital full-domes: the future of virtual astronomy education, Planetarian 34, 6 (2005).

[11] M. Zeilik, C. Schau, and N. Mattern, Misconceptions and their change in university-level astronomy courses, Phys. Teach. 36, 104 (1998).

[12] R. Wyatt, Planetarium paradigm shift, Planetarian 34, 15 (2005).

[13] C. Turk and H. Kalkan, The effect of planetariums on teaching specific astronomy concepts, J. Sci. Educ. Technol. 24, 1 (2015).

[14] K. C. Yu, K. Sahami, G. Denn, V. Sahami, and L. C. Session, Immersive planetarium visualizations for teaching solar system Moon concepts to undergraduates, J. Astron. Earth Sci. Educ. 3, 93110 (2016).

[15] J. Croft, Planetarium professionals: a balancing act to engage and educate, Planetarian 6 (2008).

[16] J. D. Plummer, S. Schmoll, K. C. Yu, and C. Ghent, A guide to conducting educational research in the planetarium, Planetarian 44, 824 (2015).

[17] D. W. Sunal, Analysis of research on the educational uses of a plantetarium, J. Res. Sci. Teach. 13, 345 (1976).

[18] N. Orion and A. Hofstein, Factors that influence learning during a scientific field trip in a natural environment, J. Res. Sci. Teach. 31, 1097 (1994).

[19] D. W. Hurd, Novelty and its relation to field trips, Education 118, 29 (1997).

[20] P. J. Green, Peer Instruction for Astronomy (Pearson Education, Inc., Upper Saddle River, NJ, 2003), ISBN 0-13-026310-9.

[21] D. Duncan, Clickers: A new teaching aid with exceptional promise, Astron. Educ. Rev. 5, 7088 (2009).
[22] E. E. Prather, A. L. Rudolph, G. Brissenden, and W. M. Schlingmann, A national study assessing the teaching and learning of introductory astronomy. Part I. The effect of interactive instruction, Am. J. Phys. 77, 320 (2009).

[23] R. H. Kay and A. LeSage, Examining the benefits and challenges of using audience response systems: A review of the literature, Comput. Educ. 53, 819 (2009).

[24] N. Hunsu, O. Adesope, and D. J. Bayly, A meta-analysis of the effects of audience response systems (clicker-based technologies) on cognition and affect, Comput. Educ. 94, 102 (2016).

[25] H. Sevian and W. E. Robinson, Clickers promote learning in all kinds of classes-small and large, graduate and undergraduate, lecture and lab, J. Coll. Sci. Teach. 40, 14 (2011).

[26] J. Wellington, Formal and informal learning in science: the role of the interactive science centres, Phys. Educ. 25, 247 (1990).

[27] R. Phillips, C. McNaught, and G. Kennedy, Towards a generalised conceptual framework for learning: The Learning Environment, Learning Process and Learning Outcomes (LEPO) framework, in Proceedings of ED-MEDIA 2010-World Conference on Educational Materials, Hypermedia \& Telecommunications, edited by J.H. C. Montgomerie (Association for the Advancement of Computing in Education, Toronto, 2012).

[28] S. A. Barab, M. Barnett, L. Yamagata-Lynch, K. Squire, and T. Keating, Using activity theory to understand the systemic tensions characterizing a technology-rich introductory astronomy course, Mind Cult. Act. 9, 76 (2002).

[29] A. Fraknoi, Insights from a survey of astronomy instructors in community and other teaching-oriented colleges in the United States, Astron. Educ. Rev. 3, 7 (2004).

[30] K. J. Small and J. D. Plummer, Survey of the goals and beliefs of planetarium professionals regarding program design, Astron. Educ. Rev. 9 (2010).

[31] I. U. for Postsecondary Research (n.d.), The Carnegie classification of institutions of higher education, 2018 edition, https://carnegieclassifications.iu.edu/ classification_descriptions/basic.php, accessed October 1, 2019.

[32] U. Eriksson, C. Linder, J. Airey, and A. Redfors, Who needs 3D when the universe is flat?, Sci. Educ. 98, 412 (2014).

[33] H. Kalkan and K. Kiroglu, Science and nonscience students' ideas about basic astronomy concepts in preservice training for elementary school teachers, Astron. Educ. Rev. 6, 15 (2007).

[34] J. Adams and T. Slater, Astronomy in the national science education standards, J. Geosci. Educ. 48, 39 (2000).

[35] National Research Council, A Framework for K-12 Science Education (The National Academies Press, Washington, DC, 2012).

[36] J. G. Manning, The role of planetariums in astronomy education, in Proceedings of an Astronomical Society of the Pacific Symposium, College Park, MD, 1994 (Astronomical Society of the Pacific, San Francisco, CA, 2009), Vol. 89.

[37] J. M. Bailey and T. Slater, A review of astronomy education research, Astron. Educ. Rev. 2 (2004). 
[38] J. D. Plummer and K. J. Small, Informal science educators' pedagogical choices and goals for learners: The case of planetarium professionals, Astron. Educ. Rev. 12 (2013).

[39] S. Swarat, G. Light, E. J. Park, and D. Drane, A typology of undergraduate students' conceptions of size and scale: Identifying and characterizing conceptual variation, J. Res. Sci. Teach. 48, 512 (2011).

[40] S. A. Sorby, Educational research in developing 3-D spatial skills for engineering students, Int. J. Sci. Educ. 31, 459 (2009).

[41] I. Heyer, S. J. Slater, and T. F. Slater, Establishing the empirical relationship between non-science majoring undergraduate learners' spatial thinking skills and their conceptual astronomy knowledge, Rev. Lat.-Am. Educ. Astron. 16, 4561 (2013).

[42] A. J. Magana, Learning strategies and multimedia techniques for scaffolding size and scale cognition, Comput. Educ. 72, 367 (2014).

[43] M. H. Schneps, J. Ruel, G. Sonnert, M. Dussault, M. Griffin, and P. M. Sadler, Conceptualizing astronomical scale: Virtual simulations on handheld tablet computers reverse misconceptions, Comput. Educ. 70, 269 (2014).

[44] M. Hegarty, Spatial thinking in undergraduate science education, Spat. Cogn. Comput. 14, 142 (2014).

[45] T. R. Tretter, M. G. Jones, and J. Minogue, Accuracy of scale conceptions in science: Mental maneuverings across many orders of spatial magnitude, J. Res. Sci. Teach. 43, 1061 (2006).

[46] K. M. Catley and L. R. Novick, Digging deep: Exploring college students' knowledge of macroevolutionary time, J. Res. Sci. Teach. 46, 311 (2009).

[47] S. Vosniadou, On the nature of naïve physics, in Reconsidering Conceptual Change: Issues in Theory and Practice, edited by M. Limón and L. Mason (Springer, Dordrecht, 2002), https://doi.org/10.1007/0-306-476371_3.

[48] C. Bakas and T. Mikropoulos, Design of virtual environments for the comprehension of planetary phenomena based on students' ideas, Int. J. Sci. Educ. 25, 949 (2003).

[49] M. G. Jones, T. A., J. Minogue, B. Broadwell, E. Wiebe, and G. Carter, Understanding scale: Powers of ten, J. Sci. Educ. Technol. 16, 191 (2007).

[50] M. K. Smith, F. H. M. Jones, S. L. Gilbert, and C.E. Wieman, The Classroom Observation Protocol for Undergraduate STEM (COPUS): A new instrument to characterize university STEM classroom practices, CBE Life Sci. Educ. 12, 618 (2013).

[51] M. Stains et al., Anatomy of STEM teaching in North American universities, Science 359, 1468 (2018).

[52] See Supplemental Material at http://link.aps.org/ supplemental/10.1103/PhysRevPhysEducRes.16.020128 for the revised planetarium usage survey, PLUS 2.0. 